\title{
Frontal Nerve
}

National Cancer Institute

\section{Source}

National Cancer Institute. Frontal Nerve. NCI Thesaurus. Code C32638.

A somatic nerve branching from the ophthalmic nerve that innervates the forehead, eye lids and frontal sinus. 